Gut, 1978, 19, 819-822

\title{
Short chain fatty acid absorption by the human large intestine
}

\author{
N. I. McNeIL, ${ }^{1}$ J. H. CUMMINGS, AND W. P. T. JAMES \\ From the MRC Dunn Nutrition Unit and Addenbrooke's Hospital, Cambridge
}

SUMMARY Short chain fatty acid absorption from the human rectum has been studied in 46 subjects attending an obesity clinic, using a dialysis bag technique. From a mixed electrolyte solution, acetate concentrations fell from 97.0 to $64.2 \mathrm{mmol} / 1$, and sodium from 97.8 to $85.1 \mathrm{mmol} / \mathrm{l}$ with respective net absorption rates of 8.1 and $5.2 \mu \mathrm{mol} / \mathrm{cm}^{2} / \mathrm{h}$. From a solution with mixed short chain fatty acids acetate concentration fell from 62.3 to $37.6 \mathrm{mmol} / 1$, propionate from 20.2 to $11.5 \mathrm{mmol} / 1$, and butyrate from 25.7 to $17.3 \mathrm{mmol} / \mathrm{l}$ with absorption rates of $5.2,1 \cdot 8$, and $1.9 \mu \mathrm{mol} / \mathrm{cm}^{2} / \mathrm{h}$. Lowering $\mathrm{pH}$ from $7 \cdot 2$ to $5 \cdot 5$, to test the possibility that absorption occurred by passive non-ionic diffusion, had no effect on absorption rates, although $\mathrm{pH}$ rose rapidly in the dialysis fluid. These results are comparable with rates of acetate absorption from the animal large intestine. The hypothesis that short chain fatty acids are not absorbed from the large gut and therefore contribute to faecal bulk by retaining water in the bowel lumen may need revision.

One of the best documented physiological actions of dietary fibre is its capacity to increase faecal bulk (Cummings et al., 1976; Mitchell and Eastwood, 1976). The greater part of this increase in faecal weight is water (Cummings et al., 1976). In vitro, fibre has been shown to have the property of holding water (McConnell et al., 1974) and it is this which is thought to account for faecal bulking. An alternative suggested mechanism is the retention in the colon of water in osmotic association with unabsorbed short chain fatty acids derived from the breakdown of fibre (Williams and Olmsted, 1936). This was thought to be the mechanism which led to diarrhoea in children with glucosidase deficiency described by Weijers et al., (1961).

Short chain fatty acids (acetic, propionic, and butyric) are the major anions in adult human faeces (Rubinstein et al., 1969) and are thought not to be absorbed by the human colon (Bustos-Fernandez et al., 1971). However, many animal studies have shown that they can absorb short chain fatty acids rapidly from the colon (Myers et al., 1967; Henning and Hird, 1972; Argenzio and Southworth, 1975) and that both ruminant and monogastric species rely on short chain fatty acids as an important source of energy.

${ }^{1}$ Present address, and address for correspondence: Department of Medicine, University College Hospital Medical School, University Street, London WC1E 6JJ.

Received for publication 29 March 1978
In the rabbit these contribute $30-40 \%$ of basal energy requirements (Parker, 1976).

The fate of short chain fatty acids in the human colon is important. They may be involved in the control of faecal bulk, are a potential source of energy and, despite the major anion in the faeces, their effect on colonic water and electrolyte transport in man is unknown. We have, therefore, studied short chain fatty acid absorption from the human rectum using the dialysis technique of Edmonds (Edmonds, 1971) and found that they are rapidly absorbed.

\section{Methods}

Forty-six subjects (10 men, 36 women, aged 16-66 years), who were patients attending an obesity clinic, volunteered to take part in the study. None had a history of colonic disease or had gastrointestinal symptoms at the time of the study. They were not fasting when studied. Absorption was measured by using a length of $8 / 32$ dialysis tubing which was mounted on a stiffened catheter, filled with test solution through the catheter using a syringe, and spigotted. The catheter was then introduced into the rectum and left for one hour (Edmonds, 1971). The average dimensions of the filled dialysis bags were $8 \times$ $0.5 \mathrm{~cm}$ and average volume $2.5 \mathrm{ml}$. Subjects were studied for either one or two separate hours. Any 
Table 1 Composition of dialysis fluid before and after one hour in rectum

\begin{tabular}{|c|c|c|c|c|c|}
\hline & & \multicolumn{2}{|c|}{ Solution I } & \multicolumn{2}{|c|}{ Solution II } \\
\hline & & Initial & Final & Initial & Final \\
\hline $\begin{array}{l}\text { Acetate } \\
\text { Propionate } \\
\text { Butyrate } \\
\text { Sodium } \\
\text { Potassium } \\
\text { Chloride } \\
\text { Bicarbonate } \\
\text { pH } \\
\text { Water loss (g) }\end{array}$ & $(\mathrm{mmol} / \mathrm{l})$ & $\begin{array}{l}97 \cdot 0 \\
\overline{-} \\
\overline{97 \cdot 8} \\
39 \cdot 6 \\
32 \cdot 9 \\
6 \cdot 5 \\
7 \cdot 21 \\
-\end{array}$ & $\begin{array}{cc}64.2 & \pm 2.5 \dagger \\
& = \\
85.1 & \pm 1.5 \dagger \\
42.5 & \pm 2.1 \\
26.9 & \pm 1.2^{*} \\
35.6 & \pm 4.0^{*} \\
7.86 & \pm 0.07 \dagger \\
0.30 & \pm 0.04\end{array}$ & $\begin{array}{c}62 \cdot 3 \\
20 \cdot 2 \\
25 \cdot 7 \\
97 \cdot 9 \\
384 \\
32 \cdot 3 \\
7 \cdot 6 \\
7 \cdot 22 \\
-\end{array}$ & $\begin{array}{cc}37.6 & \pm 1.9 \dagger \\
11.5 & \pm 0.6 \dagger \\
17.3 & \pm 0.7 \dagger \\
79.4 & \pm 2.6 \dagger \\
53.3 & \pm 4.1 * \\
25.8 & \pm 1.5 \dagger \\
41.3 & \pm 6.3 \dagger \\
8.05 & \pm 0.05 \dagger \\
0.27 & \pm 0.07\end{array}$ \\
\hline
\end{tabular}

Values are mean \pm 1 standard error.

$* \mathbf{P}<0.01, \dagger P<0.001$.

study that resulted in faecal staining of dialysis fluid in the bag was discounted.

Two solutions were used each containing sodium, potassium, chloride, bicarbonate and short chain fatty acids (Table 1). In initial studies acetate alone (solution I) was used to represent all the short chain fatty acids. Subsequently a mixture of acetate, propionate, and butyrate in the ratio of 58:19: 24 was used (solution II).

Forty-five subjects were also studied with the solutions at $\mathrm{pH} 5 \cdot 5$ instead of 7.2. This was used to test the possibility that the degree of ionisation of short chain fatty acid would affect its absorption. At pH 5.5 about $15 \%$ of the short chain fatty acids will be present unionised and so may not be available for absorption if this occurs by passive ionic diffusion. A further eight subjects were studied at $\mathrm{pH} 5.5$ only for periods of 15,30 , and 60 minutes to ascertain the rate at which $\mathrm{pH}$ changed in the dialysis bag.

Short chain fatty acids were measured by gas liquid-chromatography. 0.5 millilitres of dialysate was diluted with $4.5 \mathrm{ml}$ of a mixture of $1: 4$ formic acid: acetone AR, containing 2 methyl butyric acid as internal standard.

One microlitre injections were made on to a column of $25 \%$ NPGA on $80-100$ mesh Chromosorb W mounted on a Pye Series 104 Chromatograph at $165^{\circ}$ (Cochrane, 1975).

Water loss was estimated by weighing the catheter and dialysis bag immediately before and after the period in the rectum. Sodium and potassium concentrations were analysed using an Eel model 150 flame photometer and chloride with the BuchlerCotlove Chloridometer. Bicarbonate measurements were made by back titration of a known excess of sulphuric acid added to the sample. $\mathrm{pH}$ was measured on a Philips pH meter before the sample was frozen. Statistical analyses are by Student's $t$-test.

\section{Results (Table 1)}

Short chain fatty acids were absorbed from both
Table 2 Net movement of ions through dialysis membrane $\mu \mathrm{mol} / \mathrm{cm}^{2} / \mathrm{h}$

\begin{tabular}{lrr}
\hline & Solution I & \multicolumn{1}{c}{ Solution II } \\
\hline Acetate & $8.1 \pm 0.8$ & $5.2 \pm 0.5$ \\
Propionate & & $1.8 \pm 0.2$ \\
Butyrate & $4.7 \pm 0.8$ & $1.9 \pm 0.2$ \\
Sodium & $0.2 \pm 0.4$ & $5.0 \pm 0.5$ \\
Potassium & $1.9 \pm 0.4$ & $1.5 \pm 0.8$ \\
Chloride & $-1.7 \pm 0.3$ \\
Bicarbonate & $23.8 \pm 4.4$ & $-5.2 \pm 1.1$ \\
Water* & & $21.4 \pm 5.5$ \\
\hline
\end{tabular}

$* \mathrm{mg} / \mathrm{cm}^{2} / \mathrm{h}$.

- denotes secretion.

solutions. In solution I acetate concentration fell from 97 to $64.2 \pm 2.5 \mathrm{mmol} / 1$ after one hour in the rectum and from solution II acetate, propionate, and butyrate were all absorbed. The combined fall in concentration of the three short chain fatty acids in solution II amounted to $41.8 \mathrm{mmol} / 1$ and slightly exceeded acetate from solution I, $32 \cdot 8 \mathrm{mmol} / 1$.

When the same solutions were studied at $\mathrm{pH} 5.5$ no significant differences in the final concentrations of the short chain fatty acids were observed when compared with $\mathrm{pH} \mathbf{7 \cdot 2}$. At $\mathrm{pH} 5 \cdot 5$ solution I, final concentration of acetate $62.9 \mathrm{mmol} / \mathrm{l}$; solution II, acetate $42.4 \mathrm{mmol} / \mathrm{l}$, propionate $13.2 \mathrm{mmol} / \mathrm{l}$, and butyrate $19.0 \mathrm{mmol} / \mathrm{l}$.

Sodium and chloride concentrations also fell in both solutions and there was a net absorption of water. Potassium concentration increased slightly, the change being significant only for solution II, but the concentration of bicarbonate increased almost five-fold.

The size of the dialysis bags varied slightly between individuals so the net rate of movement of the ions through the dialysis membrane has been calculated (Table 2). This shows that acetate is lost from the dialysate at a greater rate $(8.1 \pm 0.8 \mu \mathrm{mol} /$ $\left.\mathrm{cm}^{2} / \mathrm{h}\right)$ than sodium $\left(4.7 \pm 0.8 \mu \mathrm{mol} / \mathrm{cm}^{2} / \mathrm{h}\right)$ and that the net rate of acetate transport from solution $I$ is equivalent to the net rates of the combined acetate, propionate, and butyrate in solution II $(5 \cdot 2+1 \cdot 8+$ 
$1.9 \mu \mathrm{mol} / \mathrm{cm}^{2} / \mathrm{h}$ ). Net bicarbonate secretion into the dialysis bags was $4.5 \pm 0.8$ and $5.2 \pm 1.1$ $\mu \mathrm{mol} / \mathrm{cm}^{2} / \mathrm{h}$ for the two solutions respectively and considerably exceeded chloride loss. The excess of bicarbonate over net chloride movement was approximately equivalent to the difference between sodium and short chain fatty acid loss giving an overall balance in the movement of ions. Potassium showed only small changes.

Ion movements of short chain fatty acid through the dialysis membrane at $\mathrm{pH} 5.5$ were, for acetate alone, $8.5 \pm 0.6 \mu \mathrm{mol} / \mathrm{cm}^{2} / \mathrm{h}$ and for the mixed acid solution, acetate $4.3 \pm 0.7 \mu \mathrm{mol} / \mathrm{cm}^{2} / \mathrm{h}$, propionate $1.4 \pm 0.2 \mu \mathrm{mol} / \mathrm{cm}^{2} / \mathrm{h}$, and butyrate $1.6 \pm 0.5$ $\mu \mathrm{mol} / \mathrm{cm}^{2} / \mathrm{h}$. Again net bicarbonate movement exceeded chloride movement, in the mixed acid solution $\left(4.6 \pm 0.6,3.5 \pm 0.5 \mu \mathrm{mol} / \mathrm{cm}^{2} / \mathrm{h}\right)$ and these ions moved at similar rates in the acid solution containing acetate alone at $\mathrm{pH} 5.5$ (bicarbonate $3.5 \pm 0.7$, chloride $3.6 \pm 1.2 \mu \mathrm{mol} / \mathrm{cm}^{2} / \mathrm{h}$ ).

The studies undertaken to ascertain the rate at which $\mathrm{pH}$ changed from an initial $\mathrm{pH}$ of 5.5 show that it rose rapidly. The $\mathrm{pH}$ values (means \pm standard error) for four subjects at each time were: time zero, $\mathrm{pH} 5.50 ; 15$ minutes, $\mathrm{pH} 6.62 \pm 0.04$; 30 minutes $\mathrm{pH} 7.45 \pm 0.10$ and 60 minutes, $\mathrm{pH}$ $7 \cdot 66 \pm 0 \cdot 11$. The value at 30 minutes was not significantly different from the final value.

\section{Discussion}

This study shows that the rectum, in addition to its previously demonstrated capacity to absorb water and electrolytes (Edmonds, 1971; Rask-Madsen, 1973a), is able to absorb short chain fatty acids. Rectal mucosa shows all the absorptive and secretory functions of the colon (Rask-Madsen, 1973b), although differences in the overall transport rate of electrolytes probably occur (Devroede et al., 1971).

The technique we have used to study rectal mucosal transport has been previously validated by Edmonds (1971). In rats he found no significant difference between ionic movements in a fluid free in the colonic lumen and the same fluid enclosed in a dialysis membrane. Secondly, Edmonds found in rat colon loss of ${ }^{42} \mathrm{~K}$ occurred from filled dialysis bags. Examination of the mucosa showed the radionuclide was nearly all concentrated within the area of mucosa in contact with the dialysis membrane and beyond $1 \mathrm{~cm}$ from the end of the membrane very low count rates were observed. $\mathrm{He}$ was able to recover only $5-9 \%$ of radiosodium from the lumen when dialysis bag studies were undertaken in humans. These findings support the idea that ionic movement through the dialysis bag membrane is equivalent to transport into mucosa in contact with it. The dialysis membrane is not rate limiting for electrolyte movement and in preliminary in vitro experiments we confirmed that this was so for both ionised and unionised short chain fatty acids.

Despite the important part that short chain fatty acids play in colonic physiology, only Dawson $e t$ al. (1964) have attempted to measure their absorption. They demonstrated in a single subject with an excluded colon that acetate, propionate, and butyrate were all absorbed. All the evidence from the animal world, however, indicates that man would be an exception if he did not absorb short chain fatty acids. We have demonstrated absorption rates for short chain fatty acids of between 7.7 and $8.9 \mu \mathrm{mol} / \mathrm{cm}^{2} / \mathrm{h}$ in the human rectum which are similar to those observed in animal studies-for example, 10.5 $\mu \mathrm{mol} /$ $\mathrm{cm}^{2} / \mathrm{h}$ for rumen epithelium (Stevens and Stettler, 1966); 8.6 for equine large intestine (Argenzio et al., 1974), and 9.4 in the large gut of the pig (Argenzio et al., 1975).

Whether short chain fatty acids are absorbed by ionic or non-ionic diffusion cannot be deduced from our studies. We were unable to detect a difference in absorption rates for short chain fatty acids when $\mathrm{pH}$ $5 \cdot 5$ solutions were compared with $\mathrm{pH} 7 \cdot 2$. This could be because the $\mathrm{pH}$ of the 5.5 solution rose rapidly during the first 15 minutes, so that the fatty acids would be in the ionised form largely for most of the hour as with the $\mathrm{pH} \mathbf{7 \cdot 2}$ solutions.

In the human colon a chloride-bicarbonate exchange is thought to occur (Devroede and Phillips, 1969), because more chloride than sodium is absorbed from equimolar solutions and the excess matched by secretion of bicarbonate. In this study more short chain fatty acids than sodium were absorbed and this excess was matched by excess bicarbonate secretion over chloride absorption. In the horse colon short chain fatty acid-bicarbonate exchange has been described (Argenzio et al., 1976).

The ability of the large intestine to secrete bicarbonate in exchange for other anions, both chloride and short chain fatty acids, provides considerable capacity for controlling the $\mathrm{pH}$ of luminal contents. This is shown by the rapidity with which the solution of initial pH 5.5 rose to $\mathrm{pH} 7$.

Although we have not measured the total capacity of the large bowel to absorb short chain fatty acids, this may be deduced by other means. On a typical daily intake of $20 \mathrm{~g}$ of fibre in Britain, 10-15 $\mathrm{g}$ are broken down (Southgate and Durnin, 1970). This would result in the production of at least $100 \mathrm{mmol}$ of short chain fatty acids. No figures are available for the production of short chain fatty acids from other dietary sources but a total of $5-20 \mathrm{mmol}$ of short chain fatty acids are known to be excreted daily in the faeces (Cummings et al., 1976). Thus at least 80 
mmol are unaccounted for which could be further metabolised by bacteria or absorbed and would then yield $100 \mathrm{~kJ}$. In parts of the world where fibre intakes are much higher, in the range 60-175 g daily, equivalent processes could yield appreciable quantities of metabolisable energy.

The role of short chain fatty acids in faecal bulking remains unclear. If the amount of fibre digested within the colon were the main determinant of faecal bulking then the most digestible fibre fraction would contribute most to short chain fatty acid production and most to faecal output. Yet pectin is almost completely digested in the colon and results in only a minimal increase in faecal bulk (Cummings and Southgate, unpublished observations). The fact that short chain fatty acids can be absorbed by the human colon means that a simple explanation for faecal bulking based on their production and accumulation in the bowel lumen is not possible. In view of their ready absorption, their high concentrations in faeces probably result from their being caught up in a solid mass of material and unable to diffuse readily to the mucosa, while being continually produced by colonic bacteria. Alternatively, short chain fatty acids may be retained within the colon at neutral $\mathrm{pH}$ because the absorption of associated cations like calcium and magnesium is slow. Before we can disentangle the key mechanisms which determine faecal bulking on high fibre diets we need to understand the sequence of fibre digestion and short chain fatty acid absorption in the colon.

We thank Dr A. P. Dick, Dr H. Wiggins, and Mr W. Branch for their encouragement and assistance in this project.

\section{References}

Argenzio, R. A., Lowe, J. E., and Stevens, C. E. (1976). Interrelationship of $\mathrm{Na}, \mathrm{HCO}_{3}$ and volatile fatty acid transport across equine large intestinal mucosa. (Abstract) Gastroenterology, 70, 860.

Argenzio, R. A., and Southworth, M. (1975). Sites of organic acid production and absorption in gastrointestinal tract of the pig. American Journal of Physiology, 228, 454-460.

Argenzio, R. A., Southworth, M., and Stevens, C. E. (1974). Sites of organic acid production and absorption in the equine gastrointestinal tract. American Journal of Physio$\log y, 226,1043-1050$.

Bustos-Fernández, L., Gonzales, E., Marzi, A., and Ledesma de Paolo, M. I. (1971). Fecal acidorrhea. New England Journal of Medicine, 284, 295-298.

Cochrane, G. C. (1975). A review of the analysis of free fatty acids $\left(\mathrm{C}_{2}-\mathrm{C}_{6}\right)$. Journal of Chromatographic Science,
13, 440-447.

Cummings, J. H., Hill, M. J., Jenkins, D. J. A., Pearson, J. R., and Wiggins, H. S. (1976). Changes in fecal composition and colonic function due to cereal fiber. American Journal of Clinical Nutrition, 29, 1468-1473.

Dawson, A. M., Holdsworth, C. D., and Webb, J. (1964). Absorption of short chain fatty acids in man. Proceedings of the Society for Experimental Biology and Medicine, 117, 97-100.

Devroede, G. J., and Phillips, S. F. (1969). Conservation of sodium, chloride, and water by the human colon. Gastroenterology, 56, 101-109.

Devroede, G. J., Phillips, S. F., Code, C. F., and Lind, J. F. (1971). Regional differences in rates of insorption of sodium and water from the human large intestine. Canadian Journal of Physiology and Pharmacology, 49, 1023-1029.

Edmonds, C. J. (1971). Absorption of sodium and water by human rectum measured by a dialysis method. Gut, 12 , 356-362.

Henning, S. J., and Hird, F. J. R. (1972). Transport of acetate and butyrate in the hind-gut of rabbits. Biochemical Journal, 130, 791-796.

McConnell, A. A., Eastwood, M. A., and Mitchell, W. D. (1974). Physical characteristics of vegetable foodstuffs that could influence bowel function. Journal of the Science of Food and Agriculture, 25, 1457-1464.

Mitchell, W. D., and Eastwood, M. A. (1976). Dietary fiber and colon function. In Fiber in Human Nutrition, pp. 185206. Edited by G. A. Spiller and R. J. Amen. Plenum Press: New York.

Myers, L. L., Jackson, H. D., and Packett, L. V. (1967). Absorption of volatile fatty acids from the cecum of sheep. Journal of Animal Science, 26, 1450-1458.

Parker, D. S. (1976). The measurement of production rates of volatile fatty acids in the caecum of the conscious rabbit. British Journal of Nutrition, 36, 61-70.

Rask-Madsen, J. (1973a). Simultaneous measurement of electrical polarization and electrolyte transport by the entire normal and inflamed human colon during in vivo perfusion. Scandinavian Journal of Gastroenterology, 8, 327-336.

Rask-Madsen, J. (1973b). The relationship between sodium fluxes and electrical potentials across the normal and inflamed human rectal wall in vivo. Acta Medica Scandinavica, 194, 311-317.

Rubinstein, R., Howard, A. V., and Wrong, O. M. (1969). In vivo dialysis of faeces as a method of stool analysis. IV. The organic anion component. Clinical Science, 37, 549 . 564.

Southgate, D. A. T., and Durnin, J. V. G. A. (1970). Calorie conversion factors. An experimental reassessment of the factors used in the calculation of the energy value of human diets. British Journal of Nutrition, 24, 517-535.

Stevens, C. E., and Stettler, B. K. (1966). Transport of fatty acid mixtures across rumen epithelium. American Journal of Physiology, 211, 264-271.

Weijers, H. A., Van de Kamer, J. H., Dicke, W. K., and Ijsseling, J. (1961). Diarrhoea caused by deficiency of sugar splitting enzymes. Acta Paediatrica, 50, 55-71.

Williams, R. D., and Olmsted, W. H. (1936). The effect of cellulose, hemicellulose and lignin on the weight of the stool: a contribution to the study of laxation in man. Journal of Nutrition, 11, 433-450. 